Gynecologic and

Obstetric Investigation
Gynecol Obstet Invest 2011;72:257-263

DOI: $\underline{10.1159 / 000328313}$
Received: October 12, 2010

Accepted after revision: April 10, 2011

Published online: October 13, 2011

\title{
Medical versus Surgical Abortion Methods for Pregnancy in China: A Cost-Minimization Analysis
}

\author{
Wei Xia ${ }^{a}$ Shouzhang She ${ }^{b}$ Tai Hing Lam ${ }^{c}$ \\ Departments of ${ }^{\mathrm{a}}$ Obstetrics and Gynecology, and ${ }^{\mathrm{b}}$ Anaesthesia, First Municipal Hospital of Guangzhou, Affiliated \\ to Guangzhou Medical College, Guangzhou, China; ' Department of Community Medicine, School of Public Health, \\ University of Hong Kong, Hong Kong, SAR, China
}

\section{Key Words}

Analysis of cost-effectiveness - Medical abortion •

Mifepristone $\cdot$ Misoprostol $\cdot$ Surgical abortion

\begin{abstract}
Background: Both medical and surgical abortions are popular in developing countries. However, the monetary costs of these two methods have not been compared. Methods: 430 women seeking abortions were recruited in 2008. Either a medical or surgical method was used for the abortion. We adopted the perspective of a third-party payer. Cost-minimization analysis was used based on all charges for the overall procedures in an out-patient clinic in Guangzhou, China. Results: 219 subjects $(51 \%)$ chose a medical method (mifepristone and misoprostol), whereas 211 subjects (49\%) chose a surgical method. The efficacy in the surgical group was significantly higher than in the medical group (100 vs. $90 \%, p<$ 0.001 ). Surgical abortion incurred much more costs than medical abortion on average after initial treatment. When the subsequent costs were accumulated within the 2-week follow-up, the mean total cost in the medical group increased significantly due to failure of abortion and persistent bleeding. Patients undergoing medical abortion eventually incurred equivalent expenses compared to patients under-
\end{abstract}

going surgical abortion $(p=0.42)$. Conclusions: There was no difference in the mean final costs between the two abortion methods. Complications of persistent bleeding and failure to abort (requiring surgical intervention) in the medical treatment group increased the final mean total cost substantially.

Copyright $\odot 2011$ S. Karger AG, Basel

\section{Introduction}

A combination of mifepristone followed by a prostaglandin analogue is currently the most widely used regimen for medical abortion [1-4]. Clinical effectiveness, complications, side effects and acceptability of medical versus surgical abortions has been investigated in many studies, but little attention has been paid to the economic impacts of these two approaches, especially in developing countries $[5,6]$.

With the limitation of health care resources and the increasing pressure on reducing health care expenses in developing countries, determining cost-effective means for women seeking termination of pregnancy is an important clinical as well as public health concern. We compared the clinical efficacy, complications, side effects and

\section{KARGER}

Fax +41613061234

E-Mail karger@karger.ch

www.karger.com
(C) 2011 S. Karger AG, Basel

$0378-7346 / 11 / 0724-0257 \$ 38.00 / 0$

Accessible online at:

www.karger.com/goi
Prof. Shouzhang She

Department of Anaesthesia, First Municipal Hospital of Guangzhou

Affiliated to Guangzhou Medical College, No. 1 Panfu Road

Guangzhou 510180 (China)

Tel. +861360288 4326, E-Mail rose-xw@163.com 
direct costs of the two abortion methods for gestation up to 49 days in Guangzhou, the most developed city in South China.

\section{Subjects and Methods}

\section{Subjects}

Women with gestation of up to 49 days seeking abortion at the out-patient department of the Department of Obstetrics and Gynecology, First Municipal Hospital of Guangzhou from January 1, 2008, to March 31, 2008, were included in this study. Eligible women were given the choice of either a surgical or medical method and were subsequently classified into one of two groups.

\section{Inclusion and Exclusion Criteria}

Women aged over 18 years, with a confirmed viable singleton intrauterine pregnancy of up to 49 days of gestation as assessed by pelvic ultrasound were included. Women with asthma or spasmodic bronchitis, impairment of liver or kidney function, longterm corticosteroid treatment, hemorrhagic disorder or treatment with anticoagulants, known allergy to mifepristone, breastfeeding, multiple gestation, genital tract infection, in situ intrauterine devices, adnexal masses, and severe cardiac disease were excluded.

\section{Medical Abortion}

The women who chose medical abortion were asked to take 25 $\mathrm{mg}$ mifepristone orally every $12 \mathrm{~h}$ for 3 days. Three days afterwards, they were asked to return and receive $600 \mathrm{mg}$ misoprostol orally, and were observed for $4 \mathrm{~h}$. If expulsion of the products of conception had not occurred during the 4 -hour period, they were offered an additional $600 \mathrm{mg}$ misoprostol and asked to stay for an additional $4 \mathrm{~h}$. If the expulsion of the complete gestational sac could be confirmed, the women were asked to complete a questionnaire regarding the occurrence of side effects before they were discharged from the hospital. Patients were also asked to record, over the next 14 days, the number of days vaginal bleeding occurred and to return to the clinic after 14 days for follow-up.

\section{Surgical Abortion}

Electric vacuum aspiration with a mixture of $50 \%$ nitrous oxide and 50\% oxygen for analgesia was used for surgical abortion in an out-patient theatre. All women were prescribed antibiotics for a week to prevent postabortion infection. A self-completed questionnaire was used to record any nausea, vomiting, headache, hot flushes, dizziness or chills. They were invited to return after 14 days for follow-up.

\section{Outcome Measurements}

Efficacy (success rate) was defined as the rate of complete abortion without the need for additional surgical intervention as indicated within 2 weeks of the procedure (surgical curettage for the medical group or repeat aspiration for the surgical group). The indications for surgical intervention were categorized as ongoing pregnancy, acute and severe bleeding, and incomplete abortion (retained products of conception). All tissues of expulsion from the uterus after surgical intervention were sent for histopathological examination.
Complications were defined as fatality, inpatient hospital admission, pelvic infection, blood transfusion and surgery-related complications such as uterine perforation and cervical laceration.

Side effects were defined as subjective symptoms experienced during abortion such as nausea, vomiting, headache, hot flushes, dizziness, tiredness and diarrhea as well as pain from cramping. Hemoglobin levels were measured before the abortion and at the follow-up visit 2 weeks after the treatment. The duration of bleeding was also recorded.

\section{Economic Evaluation}

An economic evaluation was performed from a third-party payer's perspective. Cost-minimization analysis was adopted as the method of economic evaluation in the present study. Costminimization analysis is one of the methods of economic evaluation, which should be undertaken only when there is evidence to suggest that outcomes of different health care interventions are the same or similar; afterwards economic analysis can concentrate on inputs and disregard consequences. The aim of cost-minimization analysis is to decide the cheapest way of achieving the same outcome. In the present study, all early pregnancies were terminated within 2 weeks using either method, and the outcomes for both groups were considered similar.

\section{Cost Calculations}

All costs incurred at the hospital were available from the hospital computer database. Costs were calculated as all charges for the overall procedures in the out-patient clinic.

Costs were divided into diagnostic, medication and therapeutic categories. Diagnostic costs included pelvic ultrasound, onestep quick urine hCG test, screening for vaginal pathogen, serum $\beta$-hCG, etc. Medication costs included mifepristone, misoprostol, uterotonics, antibiotics and hemostatics. Therapeutic costs included those of the operation, anesthesia and observation. The costs of initial treatment and potential subsequent intervention, as well as the final total cost over the whole study period were calculated for each patient.

\section{Ethical Approval}

This study was approved by the Ethics Committee of the First Municipal Hospital of Guangzhou.

\section{Statistical Methods}

The sample size calculation was based on the null hypothesis that surgical abortion is not more effective than medical abortion. Based on an estimate of $93 \%$ efficacy [7] for medical abortion and $99 \%$ efficacy [3] for surgical abortion, it was determined that 200 subjects in each group would be required for a power of $80 \%$ and a two-sided $\chi^{2}$ test with a $p$ value of 0.05 (using Stata/SE 8.0 package). To account for an expected $10 \%$ loss of follow-up among the two groups, 220 subjects were enrolled prospectively in each group.

The mean total cost was calculated for each strategy. Costs were calculated and reported in Renminbi yuan (CNY; USD $1=$ CNY 8). Student's t test was used to test for differences between means of continuous variables, and a $\chi^{2}$ test was used for categorical variables. All statistical tests were two-tailed, and $\mathrm{p}<0.05$ was considered statistically significant. 


\section{Results}

Of the 430 women included in the study, 219 (51\%) chose the medical method and 211 (49\%) chose the surgical method. The overall completion rates on the first and follow-up questionnaires were both $100 \%$.

Table 1 shows the baseline characteristics of the two groups. The two groups were similar in gestational age and previous abortion. However, the subjects undergoing medical abortion were significantly younger than those undergoing surgical abortion $(\mathrm{p}<0.05)$, and there were more unmarried, nulliparous and primigravid women in the medical group than in the surgical group (all $\mathrm{p}<$ 0.01 ).

Of the 213 women in the medical group who returned for the 2-week follow-up, the rate of complete pregnancy termination was $90 \%(192 / 213)$. The remaining 21 women were defined as failures and surgical intervention was required. After surgical curettage for failure of these 21 women, histopathologic findings of all tissues of expulsion showed residual tissues in $100 \%(21 / 21)$ of cases, and an infiltration of inflammatory cells was identified in $86 \%(18 / 21)$. In the surgical group, at the 2 -week followup, no woman was found to require a repeat vacuum aspiration. The efficacy reached 100\% (196/196).

No fatality, inpatient hospital admission, suspected pelvic infection or blood transfusion occurred in either group. No cases of complications related to surgery, such as uterine perforation or cervical laceration, were recorded.

Table 2 shows that during the medical abortion, more women experienced gastrointestinal side effects (nausea, vomiting and diarrhea) than in the surgical group. On the other hand, the main side effects of surgical abortion were tiredness, dizziness and chill. Though the majority of the women reported abdominal pain in both groups, the difference between the two groups was not statistically significant. The pain score was also similar in both groups.

The duration of bleeding lasted an average of $12.0 \pm$ 7.9 days in the medical group and $4.2 \pm 2.7$ days in the surgical group $(\mathrm{p}<0.001)$. Baseline hemoglobin levels were similar in the two groups. Hemoglobin levels in the two groups showed an average decrease of less than $1 \mathrm{~g} / \mathrm{dl}$ in both groups. Although women experienced a larger decrease in hemoglobin levels from the baseline to 2 weeks after medical abortion (from $12.6 \pm 1.0$ to 12.1 $\pm 1.5 \mathrm{~g} / \mathrm{dl}$ ) in comparison to surgical abortion, the mean changes in hemoglobin levels between the two groups were not significant $(p=0.19)$.

Medical versus Surgical Abortion

Methods for Pregnancy
Table 1. Baseline characteristics of the two study groups

\begin{tabular}{lrrr}
\hline $\begin{array}{l}\text { Baseline } \\
\text { characteristics }\end{array}$ & $\begin{array}{l}\text { Medical } \\
\text { group } \\
(\mathrm{n}=219)\end{array}$ & $\begin{array}{l}\text { Surgical } \\
\text { group } \\
(\mathrm{n}=211)\end{array}$ & $\mathrm{p}$ \\
\hline $\begin{array}{l}\text { Age, years } \\
\text { Range }\end{array}$ & $\begin{array}{r}25 \pm 5.7 \\
18-40\end{array}$ & $\begin{array}{c}28 \pm 6.1 \\
23-46\end{array}$ & 0.04 \\
$\begin{array}{l}\text { Gestational age, days } \\
\text { Marital status }\end{array}$ & $45.8 \pm 5.3$ & $46.3 \pm 5.5$ & 0.09 \\
$\quad$ Married & $81(37)$ & $114(54)$ & $<0.001$ \\
$\quad$ Not married & $138(63)$ & $97(46)$ & \\
Parity & $160(73)$ & $124(59)$ & 0.002 \\
$\quad 0$ & $59(27)$ & $87(41)$ & \\
$\quad 90(41)$ & $59(28)$ & 0.004 \\
$\begin{array}{l}\text { Primigravid } \\
\text { Prior abortion }\end{array}$ & $70(32)$ & $63(30)$ & 0.64 \\
$\quad$ Medical abortion & $32(15)$ & $39(19)$ & 0.28 \\
$\quad$ Surgical abortion & $46(21)$ & $36(17)$ & 0.30 \\
$\quad$ Both types of abortions & $8(4)$ & $12(6)$ & 0.32 \\
\hline \multicolumn{2}{l}{ Values are means \pm SD or n (\%). } & & \\
\hline
\end{tabular}

Table 2. Side effects experienced by women in the two study groups

\begin{tabular}{lccc}
\hline Side effects & $\begin{array}{l}\text { Medical group } \\
(\mathrm{n}=219)\end{array}$ & $\begin{array}{l}\text { Surgical group } \\
(\mathrm{n}=211)\end{array}$ & $\mathrm{p}$ \\
\hline Nausea & $57(26)$ & $25(12)$ & $<0.001$ \\
Vomiting & $18(8)$ & $2(1)$ & $<0.001$ \\
Diarrhea & $39(18)$ & 0 & $<0.001$ \\
Tiredness & 0 & $61(29)$ & $<0.001$ \\
Headache & $4(2)$ & $2(1)$ & 0.43 \\
Hot flushes & $11(5)$ & 0 & $<0.001$ \\
Dizziness & $13(6)$ & $76(36)$ & $<0.001$ \\
Chill & $2(1)$ & $17(8)$ & $<0.001$ \\
Abdominal pain & $182(83)$ & $179(85)$ & 0.63 \\
Pain score & $2.3 \pm 1.1$ & $2.8 \pm 1.6$ & 0.29 \\
\hline
\end{tabular}

Values are means \pm SD or $\mathrm{n}(\%)$.

The unit costs of resource items related to the two treatment strategies are shown in table 3. Table 4 shows that the mean total cost of CNY $367.56 \pm 21.31$ in the surgical group was significantly higher than that in the medical group (CNY $279.25 \pm 9.48 ; \mathrm{p}=0.01)$ after initial treatment. Of the 213 women in the medical abortion group, 21 women failed to abort and received surgical intervention. The increased costs in these women included the costs of registration, pelvic ultrasound, $\beta$-hCG test, operation, anesthetics and prophylactic antibiotics. The

Gynecol Obstet Invest 2011;72:257-263 
Table 3. Unit costs or ranges of resource items of the two study groups

\begin{tabular}{|c|c|c|c|}
\hline \multirow[t]{2}{*}{ Prices, CNY } & \multicolumn{2}{|l|}{ Medical group } & \multirow{2}{*}{$\begin{array}{l}\text { Surgical group } \\
(\mathrm{n}=211)\end{array}$} \\
\hline & $\begin{array}{l}\text { complete abortion } \\
(\mathrm{n}=197)\end{array}$ & $\begin{array}{l}\text { additional curettage } \\
(\mathrm{n}=22)\end{array}$ & \\
\hline 1. Registration cost & 4 & 4 & 4 \\
\hline \multicolumn{4}{|l|}{ 2. Diagnostic cost } \\
\hline Pelvic ultrasound & 55 & 55 & 55 \\
\hline One-step quick urine hCG test & 7 & & 7 \\
\hline Serum $\beta$-hCG & & 77 & \\
\hline Screening for vaginal pathogens & 21 & & 21 \\
\hline \multicolumn{4}{|l|}{ 3. Medication cost } \\
\hline Mifepristone (150 mg) & 48 & & \\
\hline Misoprostol (600 mg) & 28 & & \\
\hline Repeat misoprostol $(600 \mathrm{mg})^{1}$ & 28 & & \\
\hline Antibiotics $^{2}$ & $35.3-47.4$ & $35.3-47.4$ & $35.3-47.4$ \\
\hline Hemostatics $^{2}$ & $23.7-45.9$ & $23.7-45.9$ & $23.7-45.9$ \\
\hline Uterotonics ${ }^{2}$ & $17.4-34.1$ & $17.4-34.1$ & $17.4-34.1$ \\
\hline \multicolumn{4}{|l|}{ 4. Therapeutic cost } \\
\hline Perineal and vaginal douche & & 29 & 29 \\
\hline Bimanual pelvic examination & 8 & 8 & 8 \\
\hline 5. Operation cost & & 120 & 120 \\
\hline 6. Anesthetic cost & & 55 & 55 \\
\hline 7. Observational cost & 98 & & \\
\hline
\end{tabular}

Currency conversion: USD $1=$ CNY 8.

${ }^{1}$ Needed by some cases who vomited soon after the first dose administration or when no expulsion of the products of conception occurred during the first 4-hour period of observation.

${ }^{2}$ Ranges of costs for antibiotics, hemostatics and uterotonics for 1-week prescription were specified due to the diversity in different types of prescription provided by different doctors if necessary.

Table 4. Mean total cost (CNY, mean $\pm \mathrm{SD})$ for 1 patient in the two study groups ${ }^{1}$

\begin{tabular}{|c|c|c|c|}
\hline & $\begin{array}{l}\text { Medical group } \\
(\mathrm{n}=213)\end{array}$ & $\begin{array}{l}\text { Surgical group } \\
(\mathrm{n}=196)\end{array}$ & $\mathrm{p}$ \\
\hline After initial treatment & $279.3 \pm 9.5$ & $367.6 \pm 21.3$ & $0.01^{*}$ \\
\hline \multicolumn{4}{|l|}{213 women in medical group } \\
\hline With surgical intervention $(\mathrm{n}=21)$ & $664.3 \pm 53.9$ & & \multirow[t]{2}{*}{$<0.001^{* *}$} \\
\hline Without surgical intervention $(\mathrm{n}=192)$ & $338.7 \pm 35.9$ & & \\
\hline \multicolumn{4}{|c|}{192 women without surgical intervention in medical group } \\
\hline With bleeding $(\mathrm{n}=62)$ & $451.1 \pm 14.1$ & & \multirow[t]{2}{*}{$<0.001^{* *}$} \\
\hline Without bleeding $(\mathrm{n}=130)$ & $279.3 \pm 9.5$ & & \\
\hline \multicolumn{4}{|l|}{196 women in surgical group } \\
\hline After initial treatment $(\mathrm{n}=196)$ & & $367.6 \pm 21.3$ & \multirow[t]{2}{*}{$0.33^{* *}$} \\
\hline After 2-week follow-up visit $(\mathrm{n}=196)$ & & $375.2 \pm 12.8$ & \\
\hline \multicolumn{4}{|l|}{ After adding the subsequent costs within } \\
\hline the period of 2-week follow-up ${ }^{2}$ & $379.0 \pm 27.8$ & $375.2 \pm 12.8$ & $<0.42^{*}$ \\
\hline
\end{tabular}

* Horizontal comparison; ** vertical comparison.

${ }^{1}$ Compared between the surgical group and the medical group (horizontal comparison) or within the surgical/medical group (vertical comparison).

2 The figures relate to all patients in the medical and surgical groups, respectively. 
mean accumulated total cost for these 21 patients were CNY $664.28 \pm 53.93$, which increased significantly compared to women who did not require surgical intervention (CNY 338.67 \pm 35.90; $\mathrm{p}<0.001)$. Of the 192 women with confirmed successful medical abortions who did not need surgical intervention at the 2-week follow-up visit, 62 were prescribed additional antibiotics, hemostatics and uterotonics after the pelvic ultrasound and serum $\beta$-hCG test due to persistent bleeding, which could have been due to minor retained decidua or trophoblasts not detectable by ultrasound, to prevent infection and anemia and improve women's acceptance or tolerance of the medical procedures. Thus, the mean total cost increased to $\mathrm{CNY} 451.13 \pm 14.07$, which was significantly higher than in those without persistent bleeding (CNY 279.25 \pm 9.48; $\mathrm{p}<0.001)$. No women from the surgical group required repeat vacuum aspiration. Eight cases did require further serum $\beta$-hCG tests, pelvic ultrasound and additional uterotonics, hemostatics, or antibiotics due to persistent bleeding at the 2-week follow-up. These cases incurred additional costs, with the mean total cost for each patient slightly increasing from CNY $367.56 \pm 21.31$ to $375.16 \pm 12.81$, but the difference was not statistically significant $(\mathrm{p}=0.33)$. No significant difference was found in the mean total cost for the medical and surgical groups after adding the subsequent costs within the period of the 2-week follow-up ( $\mathrm{p}=0.42)$.

\section{Discussion}

In China, which has a stable number of cases asking for termination of unplanned pregnancies, women do not only consult the doctors about the differences in clinical efficacy and complications of the two approaches. Cost saving is also an important aspect of consideration because most out-patient fees are paid by the patients. The limitation of resources in health care and the increasing pressure on health care expenses also imply that physicians should not only consider the safety and efficacy of a treatment intervention, but also take into account the economic aspects as part of the clinical decision-making process and provide more information to the clients with regard to clinical and economic information [8].

In the present study, we found that the efficacy in the surgical group was significantly higher than in the medical group. Surgical abortion incurred much more costs than medical abortion on average after initial treatment. However, when the subsequent costs were accumulated within the period of the 2-week follow-up, the mean total cost in the medical group increased significantly due to failure of abortion and persistent bleeding in some cases. Thus, as a whole, patients undergoing medical abortion eventually incurred equivalent expenses compared to patients undergoing surgical abortion. To the best of our knowledge, this is the first study comparing the clinical efficacy, complications, side effects and direct cost by the two abortion methods in women with gestations up to 49 days in South China.

\section{Efficacy and Safety of the Two Abortion Methods}

Comparison of efficacy (success rate) between medical and surgical abortion is one of the key measures in our study. The timing for determining success is an important question we had to face. The timing of success varies from 2 days to 15 weeks, making comparison of efficacy in various studies problematic. In some studies $[9,10]$, expectant management became the first choice in order to handle the incomplete abortion instead of surgical intervention. Some authors did not regard prolonged bleeding or presence of tissues in the uterus as an indication for surgical intervention as they believed most incomplete abortions will become complete over time, or that the remaining tissues in the uterus would be expelled during subsequent menstrual bleeding. We defined 2 weeks as the timing of success in our study, which is quite early to determine success or failure in the course of follow-up. In our study, evidence of residual tissues and infection in the uterus was identified in some cases, and surgical evacuation of the uterus was determined to be essential. Some studies $[11,12]$ reported that necrotic decidua or trophoblasts retained in the uterus was the main cause for prolonged and heavy bleeding after medical abortion. Furthermore, heavy or prolonged bleeding can cause anemia and the risk of endometritis obviously increases over time. Our findings are similar to the findings above. Hence, it is necessary to determine success or failure earlier in the course of follow-up to prevent occurrence of infection and anemia. Additionally, although the duration of bleeding was longer in the medical group $(12.0 \pm 7.9$ days $)$ than in the surgical group $(4.2 \pm 2.7$ days), the overall changes in hemoglobin concentration between the two groups were not significantly different. Performing surgical curettage timely might be the explanation for this result, otherwise bleeding might persist and hemoglobin concentration would decrease. Note that in other studies, in comparison to women who accepted a surgical abortion, the hemoglobin level in women with prolonged bleeding left to expectant management significantly decreased. Overall, we suggest that a 2-week fol- 
low-up is necessary and adequate after the medical procedure as the timing for determining success.

A repeat oral dose of mifepristone $(25 \mathrm{mg}$ b.i.d.; total $150 \mathrm{mg}$ ) followed by misoprostol $(0.6 \mathrm{mg})$ is currently the most commonly used regimen in China. This dosage has been shown to be effective with a complete abortion rate of over $93 \%$ [4]. This regimen was adopted as the standard for our medical abortions. We found that the complete abortion rate of $90 \%$ after medical abortion was lower than that of $100 \%$ after surgical abortion, and more women experienced gastrointestinal side effects (nausea, vomiting and diarrhea) in the medical group than in the surgical group. Our lower complete abortion rate in medical abortion compared to other studies using the same regimens in China may be explained by the different followup time point. Most incomplete abortions will become complete with time, with the remaining products of conception expelled during subsequent menses [13]. In our study, the time point determining success was set at 2 weeks after the procedure, which might have resulted in more diagnoses of retained products of conception leading to more surgical interventions than in other studies with longer follow-up time. In contrast to China, vaginal administration of misoprostol is commonly used in most countries in Europe and the USA [14]. Although vaginal administration of misoprostol has fewer side effects, this method is cumbersome to administer and less acceptable to women in China. Women prefer the oral route because it is easier and more convenient and has good compliance. Even though more side effects such as cramping, nausea, vomiting and diarrhea may occur after oral administration of misoprostol in the medical group, these problems are not serious enough to result in refusal during the abortion.

A complete abortion rate of $100 \%$ in surgical abortion with no cases of surgery-related complications such as uterine perforation and cervical laceration recorded is clearly satisfactory. This can be explained by the fact that surgical abortion in China, especially in our hospital, is performed by clinicians with more experience. They have to manage many cases seeking for surgical abortion everyday due to the large population and the national policy on family planning. Only trained clinicians with adequate experience can be approved to perform the surgical abortion alone according to the local guideline. However, we found that significantly more women in the surgical group compared with the medical group had previously given birth. This might in theory confound the results: the myometrium of a parous uterus can probably better contract and expel the products of conception and the cervix can more easily dilate. Hence, fewer complications occurred after surgical abortion. Further studies including women with comparable parity are warranted.

\section{Economic Evaluation and Identification of Potential} Cost Drivers

In the present study, accounting only for initial costs, surgical abortion appeared to be $32 \%$ more expensive than medical abortion (CNY $367.56 \pm 21.31$ vs. $279.25 \pm$ 9.48). However, when the subsequent costs of examination and treatment due to incomplete abortion and bleeding within the period of 2-week follow-up were added, on average the medical group incurred almost equivalent costs as the surgical group (CNY $379.03 \pm 27.75$ vs. 375.16 \pm 12.81 ). Hence, on average the whole group undergoing medical abortion would eventually cost the same as the surgical group. Thus, these results can provide important information for those who prefer medical abortion due to its presumed lower costs.

Of the 192 women who were confirmed to have had successful medical abortions, 62 cases were prescribed additional antibiotics, hemostatics and uterotonics after the pelvic ultrasound and serum $\beta$-hCG test due to persistent bleeding. After adding the costs of these items, the mean total cost for each patient with persistent bleeding at 2-week follow-up increased from CNY $279.25 \pm 9.48$ to $451.13 \pm 14.07$. Patients with persistent bleeding had to spend approximately $62 \%$ more than those whose bleeding had ceased after the medical abortion. The relative increase was very high, which highlights persistent bleeding as a cost driver. Whether or not bleeding has ceased after a medical abortion is an important factor influencing the total cost.

Additionally, of the 213 women who underwent a medical abortion, 21 women failed to abort and received surgical intervention. The mean accumulated total cost for these 21 patients were up to CNY $664.28 \pm 53.93$ compared to $338.67 \pm 35.90$ for those whose medical abortions were successful without surgical intervention. Thus, the initial success of the medical abortion had a strong impact on the total cost, with incomplete abortions being the biggest cost driver of medical abortion.

Our study had the strengths of prospective study design (which can minimize the risk of recall and information bias), high response rates (95\%), and detailed information on total and categorical expenses. Nevertheless, our study had some limitations. Firstly, although a randomized controlled trial is an ideal design to compare these two methods, such a trial was not possible in our 
setting. As the two different abortion methods have been developed and performed for a long time in China, most women are quite familiar with the two procedures and most of them have their own method preferences when seeking abortion services. Women are not willing to be randomized due to the fear of being allocated to the treatment strategy they do not like. Patient preference is the major obstacle against randomization. Secondly, some selection bias in the present study could have come from our selection procedure because different baseline demographic characteristics between the two groups were observed. The selection bias might have a potential impact on patients' acceptability and efficacy of the procedure. Furthermore, the generalizability of our results might be limited since all abortions were performed at the same out-patient clinic of the same hospital by the same gynecologist within the same period in order to maximize the comparability of the two procedures. It is possible that our findings may differ from those with abortions done elsewhere. Finally, although our response and retention rates were rather high, women who were eligible and had completed the study might differ from those who did not. A multicenter study is warranted.

In conclusion, administration of mifepristone in combination with misoprostol is a safe and efficient alternative to the surgical abortion method in termination of early pregnancy. Studies of cost-effectiveness of abortion methods, especially in developing countries like China, can generate important local evidence to assist decision making, facilitate the best possible use and create maximum benefits of available resources.

\section{Acknowledgements}

This paper is in part based on the first author's Master of Public Health Dissertation at the School of Public Health, University of Hong Kong, Hong Kong, SAR, China.

\section{Disclosure Statement}

None.

\section{References}

1 Baird DT: Medical abortion in Britain. Br J Obstet Gynaecol 1994;101:367-368.

$\checkmark 2$ Henshaw RC: Mifepristone (RU486) and abortion. Med J Aust 1997;167:292-293.

-3 Winikoff B, Sivin I, Coyaji KJ, et al: Safety, efficacy, and acceptability of medical abortion in China, Cuba, and India: a comparative trial of mifepristone-misoprostol versus surgical abortion. Am J Obstet Gynecol 1997; 176:431-437.

4 Wu S: Medical abortion in China. J Am Med Womens Assoc 2000;55:197-199, 204.

5 Graziosi GC, van der Steeg JW, Reuwer PH, Drogtrop AP, Bruinse HW, Mol BW: Economic evaluation of misoprostol in the treatment of early pregnancy failure compared to curettage after an expectant management. Hum Reprod 2005;20:1067-1071.
6 Cowett AA, Golub RM, Grobman WA: Costeffectiveness of dilation and evacuation versus the induction of labor for second-trimester pregnancy termination. Am J Obstet Gynecol 2006;194:768-773.

7 Cheng L: Medical abortion in early pregnancy: experience in China. Contraception 2006;74:61-65.

8 Jefferson T, Demicheli V, Mugford M: Elementary Economic Evaluation in Health Care, ed 2. London, BMJ Books, 2000.

$\rightarrow$ Elul B, Ellertson C, Winikoff B, Coyaji K: Side effects of mifepristone-misoprostol abortion versus surgical abortion. Data from a trial in China, Cuba, and India. Contraception 1999;59:107-114.

10 Davis AR, Hendlish SK, Westhoff C, et al: Bleeding patterns after misoprostol vs surgical treatment of early pregnancy failure: results from a randomized trial. Am J Obstet Gynecol 2007;196:31. e1-e7.
11 Liang Y: Discussion for indications of surgical evacuation after medical abortion. J Pub Health Prev Med 2005;16:74-75.

$12 \mathrm{Xu}$ M: Observation for pathological results of curettage tissues after medical abortion. Chin J Obstet Gynecol 1994;12:739-741.

13 Jensen JT, Astley SJ, Morgan E, Nichols MD: Outcomes of suction curettage and mifepristone abortion in the United States. A prospective comparison study. Contraception 1999;59:153-159.

14 Child TJ, Thomas J, Rees M, MacKenzie IZ: A comparative study of surgical and medical procedures: 932 pregnancy terminations up to 63 days gestation. Hum Reprod 2001; 16: 67-71. 